\title{
Paediatric radiologists rise up and reach out
}

\author{
The World Federation of Paediatric Imaging
}

\author{
M. Ines Boechat
}

(C) Springer-Verlag 2011

\section{World Federation of Paediatric Imaging Launched at International Paediatric Radiology Congress}

London, May 30, 2011-The leaders of the world's regional paediatric imaging societies have united to establish the World Federation of Paediatric Imaging to address global barriers to optimal paediatric imaging care. The WFPI will promote education, best practices and appropriate imaging guidelines and work to provide better access to vital imaging care for children worldwideparticularly those in developing or war-torn areas.

Inspired by a global reach developed through years of interaction and exchange, the regional societies pioneering the federation will, in close cooperation with global health organizations, foster ties among paediatric imaging organizations around the world and serve as a unified voice on the practice of paediatric imaging.

At the opening session of the International Paediatric Radiology Congress held in London, May 27-June 1, 2011, co-presidents Drs. Dorothy I. Bulas and Catherine Owens announced the federation's launch. "This is an important, committed visionary group with a strategic plan to explore global health inequalities, which are well documented by the World Health Organization. The group aims to address these issues tactically, focusing on providing education, training and partnership across national boundaries. This has to be done to ensure that all children, including those in resource-poor countries, have access to (at the very least) basic imaging facilities, which thence may extend or save their lives," said Dr. Catherine Owens, FRCR, IPR Congress co-president and general secretary of the ESPR.

\section{I. Boechat $(\square)$}

Department of Radiology,

David Geffen School of Medicine at UCLA, (Box 951721), Los Angeles, CA 90095-1721, USA

e-mail: iboechat@mednet.ucla.edu
"Widespread computer facilities mean that we can network to remote medical sites with insufficient number of trained staff. Standard radiology equipment, an Internet connection, digital camera and a willingness to share expertise are the basic requirements to initiate this vital global initiative. The online possibilities, telemedicine and global meetings can change the imaging world map. It's up to us to harness the synergies that our different Societies can offer and reach out to breach the gap," said Dorothy Bulas, M.D., IPR Congress co-president and president of the SPR.

The founding World Federation Board chair and a former president of the North American Society for Pediatric Radiology, Dr. M. Ines Boechat trained as a doctor in Brazil. She explained the motivation behind this initiative: "Having worked extensively with Latin American, North American and European pediatric radiologists over the past 30 years, and seen the tremendous differences in practice methods and resources available around the world, it became increasingly clear to me that the integration of efforts would benefit all of us. That is my hope and inspiration for the World Federation of Pediatric Imaging."

"What's more, at this moment our colleagues the worldover are affected by trauma and upheaval, which is why some of them are not with us today. On the occasion of this launch, we unite in paying homage to them."

The founding organizations of the World Federation of Paediatric Imaging include the Asian-Oceanic Society for Paediatric Radiology (AOSPR), the European Society of Paediatric Radiology (ESPR), Sociedad Latino Americano de Radiologia Pediatrica (SLARP) and the Society for Pediatric Radiology (SPR).

Founding board members include M. Ines Boechat, M. D.; Dorothy Bulas, M.D.; Pedro Daltro, M.D.; Goya Enriquez, M.D.; In-One Kim, M.D.; Catherine Owens, M. D.; Gloria Soto, M.D., and David Springer, M.D. 